\title{
Heme iron polypeptide in treatment of anemia inpregnancy
}

\author{
Agrawal S. ${ }^{1}$, Alevoor S. ${ }^{2}$ \\ ${ }^{1}$ Dr. Shonali Agrawal, Associate Professor, ${ }^{2}$ Dr. Shruthi Alevoor, Postgraduate in Obstetrics and Gynaecology Department, \\ SSG Hospital, Vadodara, Gujarat- 390001, India.
}

Corresponding Author: Dr. Shruthi Alevoor; "SREENIVAS” Darbe, Puttur, Karnataka, India. E-mail: shruthialevoor@gmail.com

\begin{abstract}
Introduction: Treatment of iron deficiency anemia with non-heme iron salts still remains a challenge. The negative influence of various dietary elements and medications slows the absorption of iron from iron salts which makes it less bio-available, the side effects associated with iron salts, results in poor compliance. But Heme Iron Polypeptide claims to overcome the short comings of the non - heme oral iron. Materials and Methods: This prospective clinical study was done on patients of SSG Hospital, Baroda; 100 mild to moderate anemia pregnant patients between 16 to 28 weeks were included. The primary outcome of interest was mean maternal hemoglobin and serum ferritin levels at the end of treatment. Secondary outcomes were treatment related side effects and compliance. Results: There was significant rise in hemoglobin [mean difference (MD), 1.05841; $\mathrm{p}<0.001$ ] and serum ferritin [mean difference (MD) 7.3715, p, 0.001]. No side effects and good compliance with Heme Iron Polypeptide. Conclusion: Heme Iron Polypeptide is promising supplementary treatment for iron deficiency anemia in pregnancy as there was significant rise in hemoglobin and other iron indices which are comparable to oral iron salts. Heme Iron Polypeptide is a better source of iron for iron deficiency anemia in pregnancy, as it has less side effects especially gastrointestinal side effects, because of which it has better compliance.
\end{abstract}

Keywords: Oral non-heme iron, Heme Iron Polypeptide, Serum ferritin, Iron deficiency anemia

\section{Introduction}

Anemia is a major health problem in the antenatal clinics all over the world. Among the different types of anemia seen in pregnancy, the Iron deficiency type is the commonest. Prevalence of anemia in India is 53.6\% (year 2011) as per World Bank data which is almost unchanged over a decade (55\% in year 2000). The therapeutic approach in treating iron deficiency anemia includes correcting the anemia with iron supplementation and addressing the underlying cause [1].

The most widely used iron supplements are those that contain the ferrous/ferric form of iron (non-heme iron) However, iron salt therapy comes along with its own drawbacks and gastrointestinal side effects such as abdominal discomfort, nausea, vomiting, constipation, and dark colored stools. [2,3]. Certain inhibitors of iron absorption such as phytates and polyphenols have also been shown to have an inhibitory effect on iron absorption that occurs in various amounts in plant foods and beverages, such as vegetables, fruit, some cereals and legumes, tea, coffee, and wine. Animal proteins, such as

Manuscript received: $14^{\text {th }}$ August 2018

Reviewed: $24^{\text {th }}$ August 2018

Author Corrected: $30^{\text {th }}$ August 2018

Accepted for Publication: $3^{\text {rd }}$ September 2018

Obsgyne Review: Journal of Obstetrics and Gynecology milk proteins, egg proteins, and albumin, have been shown to inhibit iron absorption. Proteins from soybean also decrease iron absorption.Patient compliance to iron supplementation therapy shows a poorpicture owing to the various side effects like abdominal discomfort, nausea, vomiting and constipation [4]. Medications such as anticholesterol drugs, antacids and $\mathrm{H} 2$ receptor blockers have been shown to interfere with iron absorptionfrom nonheme iron salts.

Vitamin or mineral supplements as a treatment for any other deficiencies or ailments may also hamper iron absorption. Calcium also exerts negative effects on nonheme iron absorption. Additionally, manganese has also been shown to interfere with iron absorption because of similar physiochemical properties and shared absorptive pathways $[5,6,7]$.

Heme iron polypeptide (HIP) is a new generation oral iron which is produced by enzymatic degradation of hemoglobin from animal blood and subsequent ultrafiltration/dialysis. Its good intestinal absorption and reduced risk of gastrointestinal side-effects make it an excellent therapy to treat Iron deficiency and attendant

Available online at: www.medresearch.in 55 | P a g e 
anemia $[8,9]$. In comparison to non-heme iron, heme iron shows 2 - to 7-fold higher bioavailability [10]. The overall compliance of treatment with heme iron supplements is much better compared with non-heme iron salts [11]. Heme iron polypeptide lacks any dietary or drug interactions. Therefore, it can be taken irrespective of the meal times and be co-administered with other medications $[11,12]$.

This study was undertaken to find out the usefulness of Heme iron polypeptide for treatment of IDA in pregnancy.

\section{Objectives}

1. To study the rise of hemoglobin, total iron and serum ferritin in pregnant women with mild to moderate anemia (16-34 weeks) taking Heme Iron Polypeptide.

2. To study the side effects of Heme Iron Polypeptide

3. To study compliance of Heme iron polypeptide

\section{Materials and Methods}

Study Design: Aprospectiveclinical study

Study Setting: Baroda Medical College SSGH affiliated to MS University

Study Population: Study will be carried out on women visiting SSG HOSPITAL VADODARA out patient department of obstetrics and gynaecology who meet inclusion criteria mentioned below.

Study Duration: One year

Sampling and Sample Size: 100 patients

\section{Inclusion Criteria}

- Gestational age 16 to 28 weeks (by LMP or by USG at first trimester).

- $\mathrm{Hb} 7$ to 10.9 gms \% (Mild to Moderate anemia)

- Women with iron deficiency anemia

- Singleton pregnancy

- Mean corpuscular volume $<80 \mathrm{fl}$

- Ferritin $<12 \mathrm{ng} / \mathrm{ml}$

- Total Iron $<30 \mathrm{mcg} / \mathrm{dl}$

\section{Exclusion criteria}

- Gestational age $<16$ weeks

\section{Original Research Article}

- Gestational age $>28$ weeks

- Women with other than iron deficiency anemia

- Multiple pregnancy

- Sickle cell disease

- Women not giving consent

Methods of assigning groups: Assigning of the drug to patients who meet inclusion criteria.

Interventions and its methods: After all the patients gave written informed consent they were included in the study and before putting patients on heme iron polypeptide (HIP) baseline CBC, Serum Ferritin, Peripheral Smear, Sickling, Serum Creatinine, SGPT, Total iron was done.

Heme iron polypeptide was given once a day in cases of mild anemia ( $\mathrm{Hb} 9-10.9 \mathrm{gm} \mathrm{\%})$ and twice a day in cases of moderate anemia ( $\mathrm{Hb} 7-9 \mathrm{gm} \%$ ). One Tab vit B12 $1500 \mathrm{mcg}$ sublingual was given once a day to all the patients.

These patients are followed up at 2 weeks, 4 weeks and after 100 days. At 2 weeks only, inquiry regarding side effects was done and subjects encouraged for regular medications. At end of $4^{\text {th }}$ and $8^{\text {th }}$ week CBC and Retic count was repeated.

If at any time the subject did not show rise of retic count or wanted to discontinue the medication, she was dropped out of the study and choice of injectable iron given to her. At 100 days, CBC, S. ferritin, S. Creatinine and SGPT done.

Data Collection: Participant data including demographic characteristics, medical and pregnancy history and outcomes will be collected.

Data Analysis: Descriptive statistics (Frequency, Mean, SD, Cross tabulation and Paired test) was used for statistical analysis

Data Entry: Excel sheet

This is aprospective clinical studycarried out on women visiting SSG Hospital Vadodara outpatient department of obstetrics and gynaecology after approval from the Ethical committee of SSG Hospital.

It was carried out from June 2016 to June 2017 total number of 100 patients, who meet the inclusion criteria mentioned below 


\section{Results}

Among 100 patients 12 patients were dropped out from the study as there was no significant rise in retic count at 4 or 8 weeks and were supplemented with iron sucrose. Following are the results:

Table No1: Comparison of the pre and post Hemoglobin values.

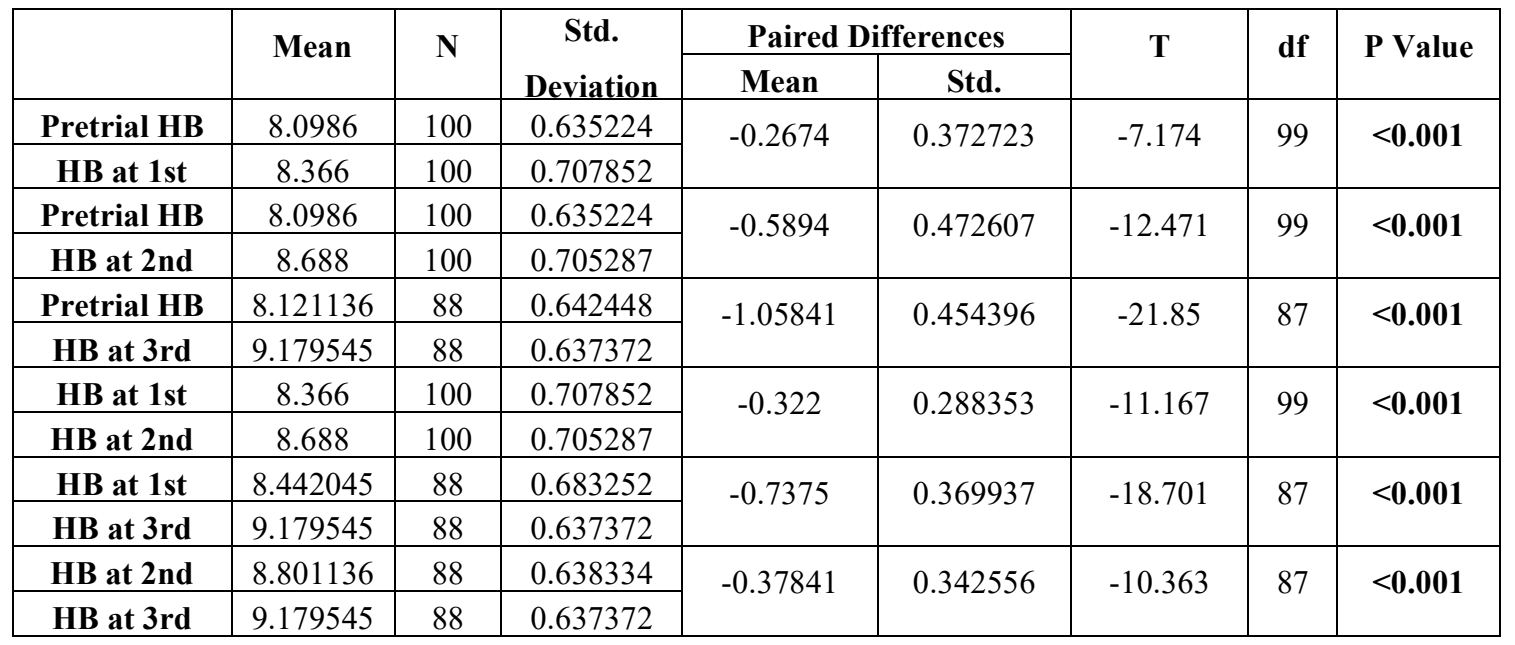

According to Table No 1:

a) On comparison of the mean values of Pretrial HB and HB at 1 st month the mean values of $\mathrm{HB}$ at $1 \mathrm{st}$ month is higher with a difference of 0.2674 is statistically significant with a $p$ value of $<0.001$.

b) On comparison of the mean values of Pretrial $\mathrm{HB}$ and $\mathrm{HB}$ at $2 \mathrm{nd}$ month the mean values of $\mathrm{HB}$ at $2 \mathrm{nd}$ month is higher with a difference of 0.5894 is statistically significant with a $\mathrm{p}$ value of $<0.001$.

c) On comparison of the mean values of Pretrial $\mathrm{HB}$ and $\mathrm{HB}$ at 3rd month the mean values of $\mathrm{HB}$ at 3rd month is higher with a difference of 1.0584091 is statistically significant with a $\mathrm{p}$ value of $<0.001$.

d) On comparison of the mean values of $\mathrm{HB}$ at 1 st month and $\mathrm{HB}$ at 2 nd month the mean values of $\mathrm{HB}$ at $2 \mathrm{nd}$ month is higher with a difference of 0.322 is statistically significant with a $p$ value of $<0.001$.

e) On comparison of the mean values of $\mathrm{HB}$ at $1 \mathrm{st}$ month and $\mathrm{HB}$ at $3 \mathrm{rd}$ month the mean values of $\mathrm{HB}$ at $3 \mathrm{rd}$ month is higher with a difference of 0.7375 is statistically significant with a $p$ value of $<0.001$.

f) On comparison of the mean values of $\mathrm{HB}$ at 2 nd month and $\mathrm{HB}$ at $3 \mathrm{rd}$ month the mean values of $\mathrm{HB}$ at $3 \mathrm{rd}$ month is higher with a difference of 0.3784091 is statistically significant with a $\mathrm{p}$ value of $<0.001$.

Table No 2: Comparison of pre and post-trial Serum Reticulocyte count values.

\begin{tabular}{|c|c|c|c|c|c|c|c|c|}
\hline & \multirow[t]{2}{*}{ Mean } & \multirow[t]{2}{*}{$\mathbf{N}$} & \multirow{2}{*}{$\begin{array}{c}\text { Std. } \\
\text { Deviation }\end{array}$} & \multicolumn{2}{|c|}{ Paired Differences } & \multirow[t]{2}{*}{$\mathbf{T}$} & \multirow[t]{2}{*}{ df } & \multirow[t]{2}{*}{ P Value } \\
\hline & & & & $\begin{array}{c}\text { Mean } \\
\text { Difference }\end{array}$ & $\begin{array}{c}\text { Std. } \\
\text { Deviation }\end{array}$ & & & \\
\hline $\begin{array}{c}\text { Pretrial } \\
\text { reticulocyte } \\
\text { count }\end{array}$ & 1.090909 & 88 & 0.29542 & 0.005682 & 0.358912 & 0.149 & 87 & 0.882 \\
\hline $\begin{array}{c}\text { Post-trial } \\
\text { reticulocyte } \\
\text { count }\end{array}$ & 1.085227 & 88 & 0.334093 & & & & & \\
\hline
\end{tabular}

On comparison of the mean values of Pretrial reticulocyte count and Post-trial reticulocyte count the mean values of Pretrial reticulocyte count is higher with a difference of 0.0056818 is statistically not significant with a $\mathrm{p}$ value of 0.882 . 
Table No 3: Comparison of pre and post trial Serum Iron values.

\section{Original Research Article}

\begin{tabular}{|c|c|c|c|c|c|c|c|c|}
\hline & \multirow[b]{2}{*}{ Mean } & \multirow[b]{2}{*}{$\mathbf{N}$} & \multirow{2}{*}{$\begin{array}{c}\text { Std. } \\
\text { Deviation }\end{array}$} & \multicolumn{2}{|c|}{ Paired Differences } & \multirow[b]{2}{*}{$\mathbf{T}$} & \multirow[b]{2}{*}{ df } & \multirow{2}{*}{$\begin{array}{c}\text { P } \\
\text { VALUE }\end{array}$} \\
\hline & & & & $\begin{array}{c}\text { Mean } \\
\text { Difference }\end{array}$ & $\begin{array}{c}\text { Std. } \\
\text { Deviation }\end{array}$ & & & \\
\hline Pretrial Iron & 24.189 & 88 & 1.6294 & \multirow[b]{2}{*}{-40.6784} & \multirow[b]{2}{*}{8.327374} & \multirow[b]{2}{*}{-45.824} & \multirow[b]{2}{*}{87} & \multirow[b]{2}{*}{$<0.001$} \\
\hline $\begin{array}{l}\text { Post-trial } \\
\text { Iron }\end{array}$ & 64.86705 & 88 & 8.955236 & & & & & \\
\hline
\end{tabular}

According to Table No 3:

On comparison of the mean values of Pretrial S. Iron and Post trial S.Iron the mean values of Post-trial S.Iron is higher with a difference of 40.6784091 is statistically significant with a $\mathrm{p}$ value of $<0.001$

Table No 4: Comparison of pre and post trial Serum MCV values.

\begin{tabular}{|c|c|c|c|c|c|c|c|c|}
\hline & \multirow[t]{2}{*}{ Mean } & \multirow[t]{2}{*}{$\mathbf{N}$} & \multirow{2}{*}{$\begin{array}{c}\text { Std. } \\
\text { Deviation }\end{array}$} & \multicolumn{2}{|c|}{ Paired Differences } & \multirow[t]{2}{*}{$\mathbf{T}$} & \multirow[t]{2}{*}{ df } & \multirow{2}{*}{$\begin{array}{c}\text { P } \\
\text { VALUE }\end{array}$} \\
\hline & & & & $\begin{array}{c}\text { Mean } \\
\text { Difference }\end{array}$ & $\begin{array}{c}\text { Std. } \\
\text { Deviation }\end{array}$ & & & \\
\hline Pretrial MCV & 73.8375 & 88 & 5.41896 & \multirow[t]{2}{*}{-18.2989} & \multirow[t]{2}{*}{4.740423} & \multirow{2}{*}{$\begin{array}{c}-- \\
36.212\end{array}$} & \multirow[t]{2}{*}{87} & \multirow[t]{2}{*}{$<0.001$} \\
\hline Post-trial MCV & 92.14 & 88 & 5.167 & & & & & \\
\hline
\end{tabular}

On comparison of the mean values of Pretrial MCV and Post-trial MCV the mean values of Post-trial MCV is higher with a difference of 18.2988636 is statistically significant with a $\mathrm{p}$ value of $<0.001$

Table No 5: Comparison of pre and post trial Serum Ferritinvalues

\begin{tabular}{|c|c|c|c|c|c|c|c|c|}
\hline Pretrial Ferritin & 9.410227 & 88 & $\begin{array}{c}0.95243 \\
7\end{array}$ & & & & & \\
\cline { 1 - 4 } $\begin{array}{c}\text { Post-trial } \\
\text { Ferritin }\end{array}$ & 16.782 & 88 & 2.1411 & -7.37159 & 2.42965 & -28.462 & 87 & $<0.001$ \\
\hline
\end{tabular}

On comparison of the mean values of Pretrial S. ferritin and Post-trial S. ferritin the mean values of Post-trial S. ferritinis higher with a difference of 7.3715909 is statistically significant with a $p$ value of $<0.001$.

Table 6: Comparison of pre and post trial Serum Creatininevalues.

\begin{tabular}{|c|c|c|c|c|c|c|c|c|}
\hline & Mean & $\mathbf{N}$ & $\begin{array}{c}\text { Std. } \\
\text { Deviation }\end{array}$ & \multicolumn{2}{|c|}{ Paired Differences } & T & df & P \\
\cline { 5 - 7 } & & & $\begin{array}{c}\text { Mean } \\
\text { Difference }\end{array}$ & $\begin{array}{c}\text { Std. } \\
\text { Deviation }\end{array}$ & & & \\
\hline PretrialS,creatinine & $\mathbf{0 . 7 4 4 4}$ & $\mathbf{9 5}$ & $\mathbf{0 . 0 8 9 8 8}$ & $\mathbf{- 0 . 0 0 4 3 2}$ & $\mathbf{0 . 0 5 9 9 6}$ & $\mathbf{- 0 . 0 7 2}$ & $\mathbf{9 4}$ & $\mathbf{0 . 4 8 5}$ \\
\cline { 1 - 3 } $\begin{array}{c}\text { Post-trial S. } \\
\text { Creatinine }\end{array}$ & 0.7487 & 95 & 0.08696 & & & & \\
\hline
\end{tabular}

On comparison of the mean values of Pretrial S. Creatinine and Post-trial S. Creatinine the mean values of Post-trial S.Creatinine is higher with a difference 0.00432 is statistically not significant with a p value of 0.485 .

\section{Discussion}

This study included hundred patients with mild to moderate anemia; these patients were treated with HIP and in whom a significant rise in $\mathrm{Hb}$ and other iron indices was seen at the end of hundred days.
The rise of $\mathrm{Hb}$ in our study after treating with HIP was comparable with rise of $\mathrm{Hb}$ after treating withoral salts (ferrous sulphate) as in a study done by Syal Neeru et al [13]. EFSA [European Food Safety Authority] conducted 
a study in which children aged between 6-36 months with iron deficiency anemia were randomized to heme iron, ferrous sulfate and placebo, while the iron supplementation [both heme and non-heme] improved hemoglobin level as well as physical condition of the children proving the therapeutic efficacy of heme iron supplementation[14]. Although, Barraclough et al, concluded that HIP[Proferrin-ES] showed no clear safety or efficacy in peritoneal dialysis patients compared with conventional oral iron supplements[15,16].

In our study there was a rise of $\mathrm{Hb}$ from 8.121136 \pm 0.642448 to $9.179545 \pm 0.637372 \mathrm{gm} / \mathrm{dl}$, which was statistically significant, there was no side effect andwas well tolerated by the patientswhich was comparable with the results study done by Abdelazim et al, which compared, HIP (oral Proferrin -ES) and intravenous iron saccharate complex (Ferrosac) in 206 pregnant women with iron deficiency anemia $(\mathrm{Hb}<10 \mathrm{gm} / \mathrm{dl})$; at the end of three months of treatment, $\mathrm{Hb}$ increased from $8.5 \pm 3.5$ to $11.3 \pm 1.3 \mathrm{gm} / \mathrm{dl}$ in HIP treatment and from $8.7 \pm 2.5$ to $11.7 \pm 0.9 \mathrm{gm} / \mathrm{dl}$ in IV iron treatment. Ferritin levels also increased in two groups.

There were no significant differences in two groups for change in $\mathrm{Hb}$ or ferritin levels.GI upset was reported in $1.6 \%$ of patients receiving oral HIP. Study reported oral HIP as effective and tolerable treatment and HIP can be considered as an alternative to intravenous iron saccharate complex for iron deficiency anemia of pregnancy.

So rise in $\mathrm{Hb}$ and serum ferritin by HIP in our study was not comparable to the results from the study by Abdelazim et al[17]. According to our study HIP is not comparable to intravenous iron saccharatecomplex, but there was statistically significantrise of $\mathrm{Hb}$ and serum ferritinin our study, but in both the studies HIP use had no side effects and was well tolerated.

Gastrointestinal side effect $\mathrm{s}$ are very common problem with oral iron preparations. Al Momen et al, in their study compared 52 women treated with intravenous iron sucrose and 59 women treated with $300 \mathrm{mg}$ oral iron sulfate, found $18(30 \%)$ of oral iron group complained of disturbing gastrointestinal symptoms and $18(30 \%)$ had poor compliance. There was no side effects and HIP was well tolerated in our study [18].

Similarly Frykman et al, conducted a double-blind study to compare the side effects and tolerability profile of heme iron and non-heme iron supplements in regular blood donors. The findings unequivocally depicted favorable tolerability profile of heme iron supplements compared to non-heme iron supplements [19].

Obsgyne Review: Journal of Obstetrics and Gynecology

\section{Original Research Article}

In our study there was significant rise in serum ferritin and serum iron, similar results were seen in the following studies. Nam et al, in their study they observed that there was a significant increase in serum iron levels, in subjects supplemented with HIP who had low serum iron levels $(<80 \mu \mathrm{dl})$ to begin with, but same was not evident in those who had normal initial iron level [20] and Seligmenet al, has noted similar findings but they had taken serum ferritin levels as a marker of body iron store.

They observed that continual supplementation of heme iron polypeptide may not lead to iron overload [21].As observed in Pizzaro et al, showed that the absolute maximum amount of iron absorbed from heme iron sources containing over $15 \mathrm{mg}$ of iron was $2 \mathrm{mg}$, whereas iron absorbed from non-heme iron salts such as ferrous sulfate progressively increased with escalating doses of ferrous sulfate. This is an important finding where the possibility of higher intake of iron or overuse of conventional iron salt can be avoided with use of HIP[22]. It is also observed that there is higher absorption with HIP compared with non-heme iron salts.

Asin Bjorn -Rasmussen et al, noted that absorption of heme iron present in a complete diet was significantly higher than that of non-heme iron; in comparison to $37 \%$ of heme iron absorption only $5 \%$ of the non-heme iron was absorbed from diet [23]. Al Monsen et al, similarly noted that absorption rate of heme iron in the diet ranged between $15-35 \%$ where as that of non heme iron was only $2-20 \%$, moreover absorption of non-heme iron was influenced by presence or absence of promoters or inhibitors in the diet [24]. Ekman and Reizenstein et al, also documented identical findings while assessing the effects of heme iron supplementation and ferrous sulfate supplementation in reproductive-aged women [25].

\section{Conclusion}

1. Heme Iron Polypeptide is a promising supplementary treatment for iron deficiency anemia in pregnancy as there was significant rise in $\mathrm{Hb}$ and other iron indices which are comparable to oral iron salts.

2. Heme Iron Polypeptide is a better source of iron for iron deficiency anemia in pregnancy, as it has less side effects especially gastrointestinal side effects, because of which it has better compliance.

\section{What this study adds to existing knowledge?}

Iron deficiency anemia is most common cause of anemia in pregnancy and most commonly iron salys is given which has less compliance and more gastrointestinal side effects but HIP has good compliance and no iron intolerance. To the best of our knowledge, the current 
study is among the fewstudies designed and conducted to evaluate the efficacy and tolerability of heme iron polypeptide in treatment of anemia in pregnancy. More studies are required to promote use of HIP in anemia in pregnancy.

This study was funded by the authors.

Acknowledgment: Authors grateful to women agreed to participate in this study.

\section{About Authors \\ $1^{\text {st }}$ Author is the person how had the idea of conducting this study and guided through this study and manuscript. \\ $2^{\text {nd }}$ Author is the person who conducted this study and prepared the manuscript.}

\section{Funding: Nil, Conflict of interest: Nil \\ Permission from IRB: Yes}

\section{References}

1. Abbaspour N, Hurrell R, Kelishadi R. Review on iron and its importance for human health. J Res Med Sci. 2014 Feb;19(2):164-74.

2. Lieu PT, Heiskala M, Peterson PA, Yang Y. The roles of iron in health and disease. Mol Aspects Med. 2001 Feb-Apr;22(1-2):1-87.

3. Soyano A, Gómez M. [Role of iron in immunity and its relation with infections]. Arch LatinoamNutr. 1999 Sep; 49 (3 Suppl 2):40S-46S.

4. Naigamwalla DZ, Webb JA, Giger U. Iron deficiency anemia. Can Vet J. 2012 Mar;53(3):250-6.

5.Alleyne M, Horne MK, Miller JL. Individualized treatment for iron-deficiency anemia in adults. Am J Med. 2008 Nov;121(11): 943-8. doi: 10.1016/j.amjmed. 2008. 07.012.

6. Johnson-Wimbley TD, Graham DY. Diagnosis and management of iron deficiency anemia in the $21 \mathrm{st}$ century. Therap Adv Gastroenterol. 2011 May; 4 (3):17784. doi: $10.1177 / 1756283 \times 11398736$.

7. Miller JL. Iron deficiency anemia: a common and curable disease. Cold Spring HarbPerspect Med. 2013 Jul 1; 3 (7). pii: a011866. doi: 10.1101/cshperspect.a011866.

8. Nagaraju SP, Cohn A, Akbari A, et al. Heme iron polypeptide for the treatment of iron deficiency anemia in non-dialysis chronic kidney disease patients: a randomized controlled trial. BMC Nephrol. 2013 Mar 20; 14: 64. doi: 10.1186/1471-2369-14-64.

\section{Original Research Article}

9. Park K, Kim H, Han M, et al. Heme iron polypeptide polymer with high iron content as an ideal iron supplement. Journal of Food Biochemistry.2010; 34(4); 896-904. doi.org/10.1111/j.1745-4514.2010.00342.x

10. EFSA Panel on Food Additives and Nutrient Sources added to Food (ANS). Scientific Opinion on the safety of heme iron (blood peptonates) for the proposed uses as a source of iron added for nutritional purposes to foods for the general population, including food supplements. EFSA Journal.2010; 8(4):1585.doi: 10.2903/j.efsa. 2010. 1585 .

11. Heme Iron Polypeptide (Proferrin) versus Oral and Injectable Iron Products for the Treatment of Anemia. https://www.cadth.ca $>$ media $>$ pdf $>$ htis

12. Pal, B., Deshpande, H., Sundari, T., Biniwale, P. Shah, K., Goel, S., Khurana, A., Qamra, A., Motlekar, S. and Barkate, H. Heme Iron Polypeptide in Iron Deficiency Anemia of Pregnancy: Current Evidence. Open journal of Obstetrics and Gynecology,2017;7,420-431. doi:10.4236/ ojog.2017.74044

13. SyalNeeru, N. Sreekumaran Nair and Lavanya Rai; Iron Sucrose Versus Oral Iron Therapy in Pregnancy Anemia. Indian Journal of Community Medicine. 2012 Oct-Dec;37(4):214-218. doi:10.4103/0970-0218.103467.

14. Barraclough KA, Noble E, Leary D, et al. Rationale and design of the oral HEMe iron polypeptide Against Treatment with Oral Controlled Release Iron Tablets trial for the correction of anaemia in peritoneal dialysis patients (HEMATOCRIT trial). BMC Nephrol. 2009 Jul 28;10:20. doi: 10.1186/1471-2369-10-20.

15. Barraclough KA, Brown F, Hawley CM, et al. A randomized controlled trial of oral heme iron polypeptide versus oral iron supplementation for the treatment of anaemia in peritoneal dialysis patients: HEMATOCRIT trial. Nephrol Dial Transplant. 2012 Nov;27(11):4146-53. doi: 10.1093/ndt/gfs372. Epub 2012 Sep 7.

16. Abdelazimn, I.a, Abu-Faza, M., Eliaa, A.A.M, Othman, H.S, Alsharif, D.A and Elsawah, W.F. Heme Iron Polypeptide (Proferrin -ES) versus Iron Saccharate Complex (Ferrosac) for Treatment of Iron Deficiency Anemia during Pregnancy. Acta Med Int 2017:4,5661.doi:10.5530/ami.2017.4.11.

17. al-Momen AK, al-Meshari A, al-Nuaim L, et al. Intravenous iron sucrose complex in the treatment of iron deficiency anemia during pregnancy. Eur J Obstet Gynecol Reprod Biol. 1996 Nov;69(2):121-4. 
18. Frykman E, Bystrom M, Jansson U, et al. Side effects of iron supplements in blood donors: superior tolerance of heme iron. J Lab Clin Med. 1994 Apr;123(4):561-4.

19.Nam,T.,Shim,J.Y.,Kim,B.,Rah,S.Y.,Park,K.,Kim,S.,M un,E.G.,Jeong,Y.J.,Han,M.K.,Cha,Y.S.,Chae,S.W.,Im,M.. and Kim, U.H. Clinical Study on the Iron Absorption from Heme- Iron Polypeptide and Non heme -Iron. Nutritional Sciences,2006; 9,295-300.

20. Wish JB, Fourtner P, Ghaddar S, Moore GM. The biological and economic value of oral organic iron in maintenance dialysis. Nephrol News Issues. 2002 Mar; 16 (4):32-3, 37-9.

21. Pizarro F, Olivares M, Hertrampf E et al. Heme-iron absorption is saturable by heme-iron dose in women. $\mathrm{J}$ Nutr. 2003 Jul;133(7):2214-7.

\section{Original Research Article}

22. Björn-Rasmussen E, Hallberg L, Isaksson B, Arvidsson B. Food iron absorption in man. Applications of the two-pool extrinsic tag method to measure heme and nonheme iron absorption from the whole diet. J Clin Invest. 1974 Jan;53(1):247-55. DOI: $10.1172 / \mathrm{JCI} 107545$

23. Monsen ER. Iron nutrition and absorption: dietary factors which impact iron bioavailability. J Am Diet Assoc. 1988 Jul;88(7):786-90.

24. Ekman M, Reizenstein P. Comparative absorption of ferrous and heme-iron with meals in normal and iron deficient subjects. Z Ernahrungswiss. 1993 Mar; 32 (1): 67-70.

\section{How to cite this article?}

Agrawal S, Alevoor S. Heme iron polypeptide in treatment of anemia inpregnancy. Obs Rev:J obstet Gynecol 2018;4 (3): 55-61.doi:10.17511/joog.2018.i03.03. 